University of Nebraska - Lincoln

DigitalCommons@University of Nebraska - Lincoln

USDA Wildlife Services - Staff Publications

U.S. Department of Agriculture: Animal and Plant Health Inspection Service

2021

\title{
Surveys for ticks on wildlife hosts and in the environment at Asian longhorned tick (Haemaphysalis longicornis)-positive sites in Virginia and New Jersey, 2018
}

\author{
Seth A. White \\ University of Georgia \\ Sarah N. Bevins \\ USDA National Wildlife Research Center \\ Mark G. Ruder \\ University of Georgia \\ David Shaw \\ University of Georgia \\ Follow this and additional works at: https://digitalcommons.unl.edu/icwdm_usdanwrc \\ Jageyt of Yhigil Natural Resources and Conservation Commons, Natural Resources Management and \\ University of Georgia \\ Policy Commons, Other Environmental Sciences Commons, Other Veterinary Medicine Commons, \\ Population Biology Commons, Terrestrial and Aquatic Ecology Commons, Veterinary Infectious Diseases \\ Seenmextpalget fomaddithocralladithoysand Immunobiology Commons, Veterinary Preventive Medicine, \\ Epidemiology, and Public Health Commons, and the Zoology Commons
}

White, Seth A.; Bevins, Sarah N.; Ruder, Mark G.; Shaw, David; Vigil, Stacey L.; Randall, Adam; DeLiberto, Thomas J.; Dominguez, Kristen; Thompson, Alec T.; Mertins, James W.; Alfred, Jeffrey T.; and Yabsley, Michael J., "Surveys for ticks on wildlife hosts and in the environment at Asian longhorned tick (Haemaphysalis longicornis)-positive sites in Virginia and New Jersey, 2018" (2021). USDA Wildlife Services - Staff Publications. 2447.

https://digitalcommons.unl.edu/icwdm_usdanwrc/2447

This Article is brought to you for free and open access by the U.S. Department of Agriculture: Animal and Plant Health Inspection Service at DigitalCommons@University of Nebraska - Lincoln. It has been accepted for inclusion in USDA Wildlife Services - Staff Publications by an authorized administrator of DigitalCommons@University of Nebraska - Lincoln. 


\section{Authors}

Seth A. White, Sarah N. Bevins, Mark G. Ruder, David Shaw, Stacey L. Vigil, Adam Randall, Thomas J. DeLiberto, Kristen Dominguez, Alec T. Thompson, James W. Mertins, Jeffrey T. Alfred, and Michael J. Yabsley 


\title{
Surveys for ticks on wildlife hosts and in the environment at Asian longhorned tick (Haemaphysalis longicornis)-positive sites in Virginia and New Jersey, 2018
}

\author{
Seth A. White ${ }^{1,2}$ (D) | Sarah N. Bevins ${ }^{3}$ | Mark G. Ruder ${ }^{1}$ | David Shaw ${ }^{1}$ | \\ Stacey L. Vigil ${ }^{1}$ | Adam Randall ${ }^{4}$ | Thomas J. Deliberto ${ }^{3}$ | Kristen Dominguez ${ }^{1}$ | \\ Alec T. Thompson ${ }^{1}$ | James W. Mertins ${ }^{5}$ | Jeffery T. Alfred ${ }^{5} \mid$ Michael J. Yabsley $^{1,2}$ (D)
}

${ }^{1}$ Southeastern Cooperative Wildlife Disease Study, Department of Population Health, College of Veterinary Medicine, University of Georgia, Athens, GA, USA

${ }^{2}$ Warnell School of Forestry and Natural Resources, University of Georgia, Athens, GA, USA

${ }^{3}$ US Department of Agriculture, Animal and Plant Health Inspection Service, Wildlife Services, National Wildlife Disease Program, Fort Collins, CO, USA

${ }^{4}$ US Department of Agriculture, Animal and Plant Health Inspection Service, Wildlife Services, National Wildlife Research Center, Pittstown, NJ, USA

${ }^{5}$ US Department of Agriculture, Animal and Plant Health Inspection Service, Veterinary Services, Diagnostics and Biologics, National Veterinary Services Laboratories, Ames, IA, USA

Correspondence

Michael J. Yabsley Southeastern

Cooperative Wildlife Disease Study, Department of Population Health, College of Veterinary Medicine, University of Georgia, Athens, Georgia, USA.

Email: myabsley@uga.edu

Funding information

US Department of Interior, Grant/Award Number: G11AC20003; Animal and Plant Health Inspection Service, Grant/ Award Number: 91130808CA; National Institutes of Health, Grant/Award Number: GM109435

\begin{abstract}
Haemaphysalis longicornis, the Asian longhorned tick (ALT), is native to eastern Asia, but it has become invasive in several countries, including Australia, New Zealand and recently in the eastern United States (US). To identify wild mammal and avian host species in the US, we conducted active wildlife surveillance in two states with known ALT infestations (Virginia and New Jersey). In addition, we conducted environmental surveys in both states. These surveillance efforts resulted in detection of 51 ALTinfested individuals from seven wildlife species, including raccoon (Procyon lotor), Virginia opossum (Didelphis virginiana), red fox (Vulpes vulpes), woodchuck (Marmota monax), eastern cottontail (Sylvilagus floridanus), striped skunk (Mephitis mephitis) and white-tailed deer (Odocoileus virginianus). We found ALT in the environment in both states and also collected three native tick species (Amblyomma americanum, Dermacentor variablis and Ixodes scapularis) that are vectors of pathogens of public health and veterinary importance. This study provides important specific information on the wildlife host range of ALT in the US.
\end{abstract}

\section{KEYWORDS}

epidemiology, introduced species, Ixodidae, public health, ticks, wild animals 


\section{1 | INTRODUCTION}

Territorial invasions by pathogen vector species, such as ticks and mosquitoes, have received substantial scrutiny because of their relevance to human and animal health (Burridge, 2011; Burridge, Simmons, \& Allan, 2000; Juliano \& Lounibos, 2005; Keirans \& Durden, 2001; Lounibos, 2002). In many parts of the world, official inspectors at ports of entry routinely monitor for ticks and other possible vector species on imported animals (Keirans \& Durden, 2001; Pietzsch, Quest, Hillyard, Medlock, \& Leach, 2006). Despite this scrutiny, ticks may be missed, resulting in introductions outside of quarantine conditions. Ticks also may be introduced by other means, such as movement by humans or via wildlife migrations (Burridge, 2011; Keirans \& Durden, 2001; Molaei, Karpathy, \& Andreadis, 2019; Mukherjee et al., 2014).

The Asian longhorned tick (ALT, Haemaphysalis longicornis) is native to East Asia, and it has a history of invasion in other regions of Asia and Oceania, including New Zealand, Australia and multiple Pacific islands, partially due to both its unusual ability to reproduce parthenogenetically and its broad host range (Heath \& Hardwick, 2011). In the United States (US), it was first identified outside of quarantine in New Jersey during 2017 on a domestic sheep that had no travel history (Rainey, Occi, Robbins, \& Egizi, 2018). Prompt control efforts in New Jersey were focused on the index site, but the following year, environmental and vertebrate host sampling confirmed ALT had overwintered locally, and the tick was subsequently detected in several other states as well. Moreover, archived immature tick specimens from 2010 and 2013, which were initially identified as Haemaphysalis leporispalustris, were re-identified as ALT, and together, this body of evidence proves that this tick is firmly established in the US and had been present long before it was initially detected (Beard et al., 2018).

The medical and the veterinary communities are concerned about the establishment of ALT in the US because of its potential roles as a livestock pest and as a pathogen vector. In Asia, ALT transmits numerous pathogens, including severe fever with thrombocytopenia syndrome (SFTS) virus, which has a case fatality rate of up to $30 \%$ in humans (Yu et al., 2011). This tick commonly infests livestock in its native and introduced ranges, where it is a vector of pathogens, such as Theileria spp., and where intense infestations can lead to production losses and deaths (Dicker, 1978; Heath, 2016; McFadden et al., 2016; Neilson \& Mossman, 1982). This concern is highlighted by the recent detection of Theileria orientalis lkeda subtype associated with cattle mortalities in Virginia (Oakes et al., 2019) and ALT-induced exsanguination of heavily infested cattle in North Carolina (North Carolina Department of Agriculture \& Consumer Services, 2019).

In response to the 2017 discovery of ALT on a sheep in New Jersey, we pursued active ALT surveillance on potential wildlife hosts and in their local habitats in 2018 to determine if this tick had become established on local native wildlife in the US. Concurrently, we conducted surveillance for ALT on wildlife hosts and in the environment on a Virginia cattle farm, following the detection of $T$. orientalis Ikeda strain, which was associated with cattle mortalities (Oakes et al., 2019). The goals of these surveillance activities were to 1 ) determine if ALT was established on wildlife at these locations, and if so, 2) define the wildlife host range for ALT. In this report, we present the combined findings from tick surveys conducted between April 2018 and August 2018 on wildlife and in the environments at three distinct locations in New Jersey and Virginia.

\section{2 | MATERIALS AND METHODS}

\section{1 | General}

We collected ticks from wild mammals and birds sampled over three separate collection periods in two states during 2018. At all study sites, we captured meso-mammals with live traps (Havahart ${ }^{\circledR}$, Lititz, PA, and Tomahawk Live Trap, Tomahawk, WI) baited with wet dog food, and small mammals with Sherman live traps (H.B. Sherman Traps, Tallahassee, FL) baited with peanut butter cereal. We set live traps in the afternoons and checked them before 10:00 a.m. the following day. For reasons of access, security from tampering and maximizing catch success, we did not randomize the placement of traps at any location.

General information on ectoparasite collections is provided here, but additional details about collections in each state are provided below. We visually examined all captured animals for ectoparasites. The entire bodies of meso-mammals were systematically examined by combing back the fur to expose the skin. Small mammals (rodents) were individually transferred to mesh bags and physically restrained for examination. The faces of birds were simply inspected, and the rest of their bodies were examined by blowing back feathers. We collected all observed adult and nymphal ticks from examined hosts, except for those on a single intensely infested white-tailed deer (Odocoileus virginianus) in Virginia, from which we took only a sample of ticks. Although we collected all larval ticks from small mammals, passerines, and a single red fox (Vulpes vulpes) with few ticks, not all larvae were collected from infested raccoons (Procyon lotor) and Virginia opossums (Didelphis virginiana) when they had very high tick intensities $(n>100)$. After collection, ticks were stored in $70 \%$ ethanol and morphologically identified at the SCWDS or the USDA National Veterinary Services Laboratories (NVSL; Ames, IA) (Clifford, Anastos, \& Van der Borght-Elbl, 1961; Durden \& Keirans, 1996; Egizi et al., 2019; Keirans \& Durden, 1998; Keirans \& Litwak, 1989).

\subsection{Wildlife collections in New Jersey}

We sampled wildlife at two sites: on private lands in Hunterdon County from 24 April-5 May 2018, and at Watchung Reservation in Union County from 5-10 May and 24 July-4 August 2018. At these sites, we euthanized meso-mammals before examination, but rodents and passerine birds were released after examination. 
In Hunterdon County, we deployed 25 live traps and 20 Sherman traps for ten consecutive nights, for a total of 250 meso-mammal and 200 small mammal trap nights. Traps were relocated within the sites after nights three and six. Sampled habitats ranged across mixed hardwoods, mixed pine, early stage successional and field edges. White-tailed deer were lethally collected prior to the trapping period (February-April).

The Union County site is a public access county park that sees $90,000+$ visitors annually. It is in a valley of mixed hardwoods, with occasional small meadows, a creek and a small lake in the bottom lands. We deployed 25 live traps and 20 Sherman traps for five consecutive nights in May, for a total of 125 meso-mammal and 100 small mammal trap nights, and for nine consecutive nights in July August, for a total of 225 meso-mammal and 180 small mammal trap nights.

We captured passerine birds using mist nets (Avinet, Portland, ME) at targeted locations for optimal capture of individuals. We carefully extracted birds from the nets, immediately examined them for ticks, and released them at capture sites. Mist nets were open daily and continuously monitored from 6:00-9:00 a.m. We also examined hunter-harvested wild turkeys (Meleagris gallopavo) made available for study by the New Jersey Division of Fish and Wildlife.

\subsection{Wildlife collections in Virginia}

We collected wildlife from locations in Albemarle County for seven days from 6-12 June 2018. Our wildlife sampling efforts were in response to the detection of $T$. orientalis and ALT in a local cattle herd (Oakes et al., 2019), and we targeted our collection sites to places within $3 \mathrm{~km}$ of the index farm.

We trapped small and meso-mammals as described for $\mathrm{New}$ Jersey, but we also used cable restraint or foot encapsulating traps for meso-mammals (Duke Traps, West Point, MS). We baited live traps with marshmallows, sardines and wet cat food. We euthanized captured animals and inspected them for ticks, except for lactating females, which were immediately released without inspection. We also collected ticks opportunistically from wildlife found dead (e.g. vehicle strike).

\subsection{Environmental sampling for ticks}

We conducted environmental sampling for ticks at all sites during the same time frames that vertebrate hosts were sampled, except we did not sample the environment in Hunterdon Co., New Jersey, in July-August 2018. We used tick drags and tick traps to collect questing ticks. The tick drags used a $1-\mathrm{m}^{2}$ felt cloth. Each individual drag transect was approximately $100 \mathrm{~m}$ long, with collectors stopping every 10-20 m to remove ticks from the cloth and preserve them in $70 \%$ ethanol. We also used carbon dioxide $\left(\mathrm{CO}_{2}\right.$; dry ice) traps. These dry ice traps consisted of a cardboard/poster board base, with 1.0-1.5 kg of dry ice pellets placed in the centre, and the edges lined with double-sided carpet tape. Additional pellets were spread lightly in the general area (up to $3.5 \mathrm{~m}$ in radius) of each trap to stimulate nearby ticks. We set up traps in mid-morning to late morning, checked them around noon and picked them up in mid-afternoon to late afternoon. In Virginia only, we also used a second type of dry ice trap, consisting of the same tape-lined cardboard base, but baited with 2-2.5 kg of dry ice pellets housed in a closed foam cooler with perforations on the sides allowing the $\mathrm{CO}_{2}$ to escape. These traps were left overnight and then examined for ticks. Any trapped ticks were removed and stored in $70 \%$ ethanol. General locations for tick traps and drags were based on locations where ALT had previously been identified. The overall goal of this sampling was to detect ALT so multiple habitat types were sampled and were chosen based on expected presence of ticks (tall grass, brushy areas, wooded areas).

\section{3 | RESULTS}

\section{1 | Wildlife sampling}

We collected numerous specimens of ALT on meso-mammal hosts at each sampling site, and all adult ALT collected were females (Table 1). In New Jersey, we found ALT on raccoons, Virginia opossums, a red fox, a woodchuck (Marmota monax) and a white-tailed deer. Similarly, we documented a diverse host range for ALT in Virginia, including raccoons, Virginia opossums, woodchucks, an eastern cottontail rabbit (Sylvilagus floridanus), a striped skunk (Mephitis mephitis) and a white-tailed deer. Our efforts failed to find ALT on any small mammal or avian species.

We found high prevalences of ALT on raccoons (>71\%) during three of the four sampling periods at the Union County, New Jersey, and at the Albemarle County, Virginia sites (Table 1). We also found high prevalences of ALT on Virginia opossums. Infestations were detected on an eastern cottontail rabbit, a striped skunk and woodchucks, although sample sizes were lower. The single white-tailed deer sampled in Virginia was found dead in a field near a sampling site, and this animal was intensely infested (>1,000 ticks). Although only a subset of ticks was collected and counted from this deer, nearly all were ALT.

In addition to ALT, we encountered five native tick species on wildlife in New Jersey and six native tick species in Virginia (Table 1). Dermacentor variablis adults were common on raccoons (>70\% prevalence in every sample collection) and on Virginia opossums (100\% prevalence for three collection periods, $20 \%$ for the other). We found Amblyomma americanum only at the Virginia sites, where it was common on several host species including raccoons, Virginia opossums, woodchucks, eastern grey squirrels (Sciurus carolinensis) and whitetailed deer. We found Ixodes scapularis at all sites and during each collection period, and it infested a greater variety of hosts than any other encountered native tick species. Ixodes cookei infested five species including raccoons, Virginia opossums, red foxes, striped skunks and woodchucks, but Ixodes texanus infested only raccoons. 


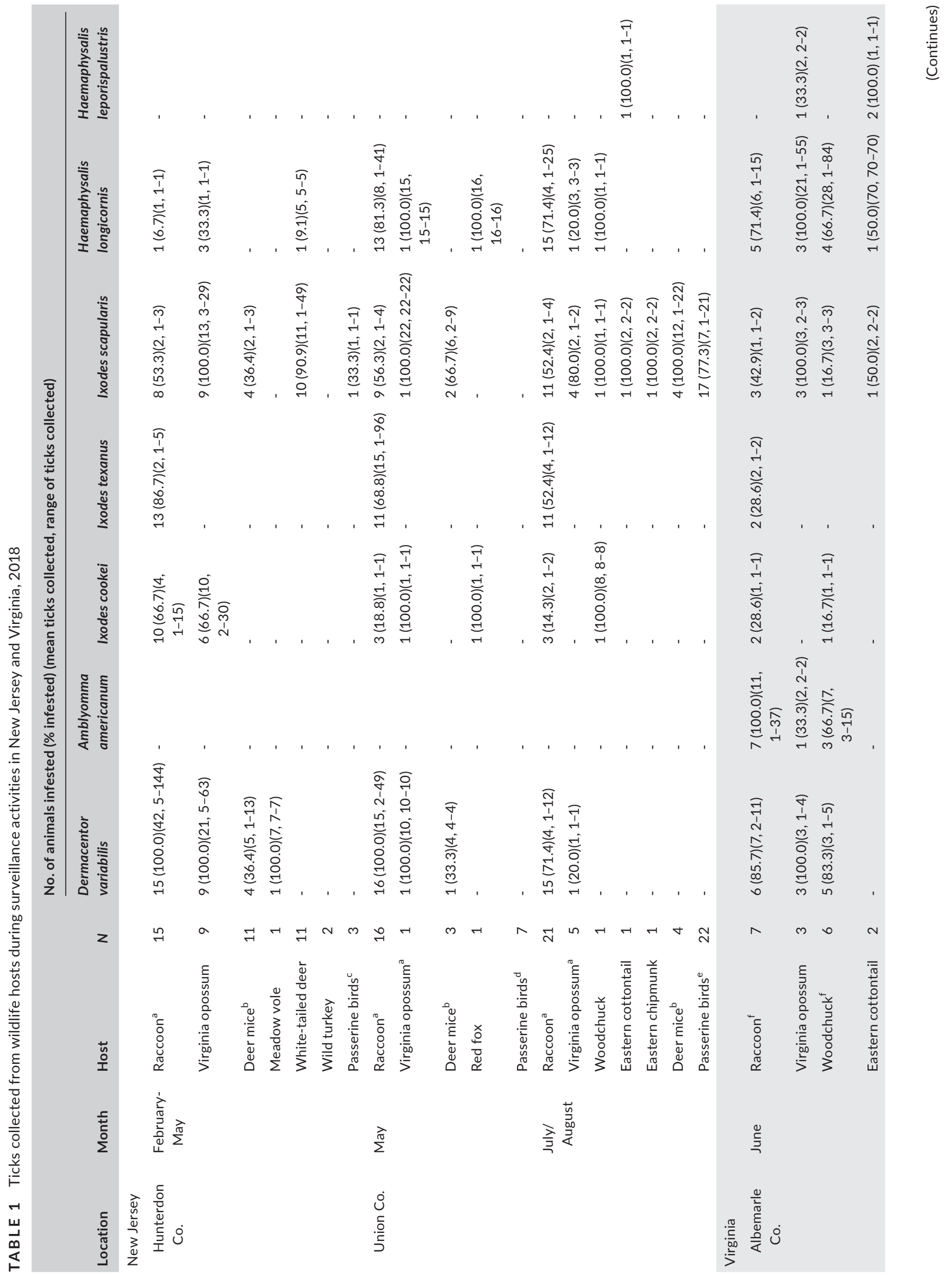




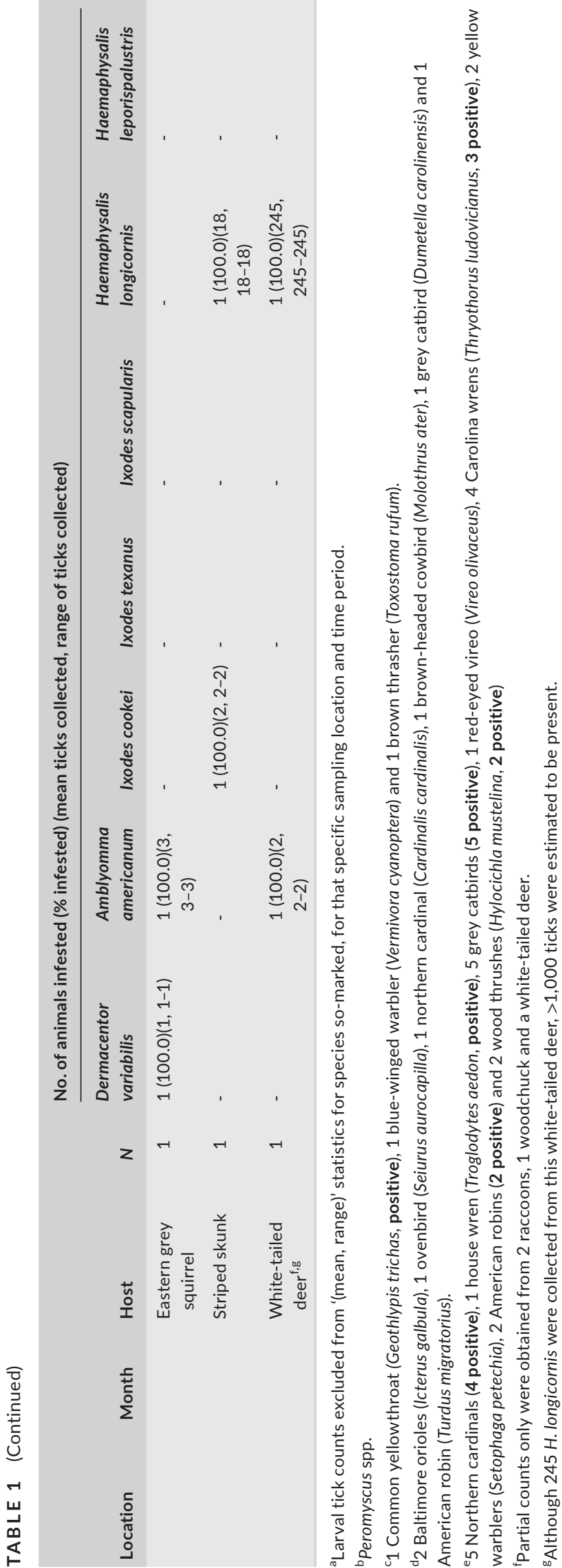

Finally, $H$. leporispalustris was found on nearly all sampled eastern cottontail rabbits, and one rabbit in Virginia was co-infested with both $\mathrm{H}$. leporispalustris and ALT (Table 1).

\section{2 | Environmental sampling}

We collected four species of ticks using tick drag and $\mathrm{CO}_{2}$ trapping methods (Table 2). At the Union County, New Jersey, site only, we collected 72 ALT using both collection methods combined, and most were nymphs (63\% of ticks). We collected low numbers of both $D$. variabilis and I. scapularis at both New Jersey locations using these methods. At the Virginia sites, we found low numbers of both $D$. variabilis and A. americanum and very high numbers of ALT. Of the 3,897 ALT collected by environmental sampling in Virginia, 3,582 (92\%) were nymphs. The remaining ALT were larvae (6\%) and adult females (2\%).

\section{4 | DISCUSSION}

We collected ALT at all sites and during all survey periods. Some of these data previously were presented in summary form by Beard et al. (2018), but the current report provides details on each of the surveillance efforts, including locality data, sample sizes and hosttick associations. We confirm that ALT is present at the sites sampled in New Jersey and Virginia where all three active life stages were present on numerous hosts and in their habitats. In addition to providing more detailed location records, we also document a diverse wildlife host range for ALT in North America, including several new host-tick associations.

The broad host range we observed for ALT is generally consistent with its host preferences in its native and previously introduced ranges. In these regions, the tick uses livestock as primary hosts, but it commonly occurs on a variety of domestic and wild mammals and birds (Choi et al., 2014; Greay et al., 2016; Heath, 2016; Iwakami, Ichikawa, \& Inokuma, 2014; Kim et al., 2011, 2014; Neilson \& Mossman, 1982). In our study, commonly infested hosts included raccoons, Virginia opossums and woodchucks. We also detected ALT on several eastern cottontail rabbits and striped skunks, though we only examined a small number of these animals. Previously, whitetailed deer, raccoons, Virginia opossums and woodchucks were reported as wild ALT hosts (Beard et al., 2018; Tufts et al., 2019), but red foxes, eastern cottontail rabbits and striped skunks are new host records for this invasive tick in the US. All of these hosts occur widely across the US, and thus, they could potentially serve as important, readily available maintenance hosts for ALT. Furthermore, such a diverse wildlife host range will greatly complicate any ALT mitigation effort focused on livestock or domestic animals.

We found all three active stages of ALT on raccoons, Virginia opossums and white-tailed deer. A recent study in Japan also found all three active stages of ALT on introduced raccoons, further highlighting the possible importance of this species as a host 
TAB LE 2 Ticks collected during environmental surveillance in New Jersey and Virginia, 2018

\begin{tabular}{|c|c|c|c|c|c|c|c|}
\hline \multirow[b]{3}{*}{ Location } & \multirow[b]{3}{*}{ Month } & \multirow[b]{3}{*}{$\begin{array}{l}\text { Collection } \\
\text { method }\end{array}$} & \multirow[b]{3}{*}{$N$} & \multicolumn{4}{|c|}{$\begin{array}{l}\text { No. of positive traps/drags (\% of traps/drags positive) (mean number of ticks collected, } \\
\text { range) }\end{array}$} \\
\hline & & & & \multicolumn{4}{|c|}{ (\# larvae, \# nymphs, \# adults) } \\
\hline & & & & $\begin{array}{l}\text { Dermacentor } \\
\text { variabilis }\end{array}$ & $\begin{array}{l}\text { Amblyomma } \\
\text { americanum }\end{array}$ & Ixodes scapularis & $\begin{array}{l}\text { Haemaphysalis } \\
\text { longicornis }\end{array}$ \\
\hline \multicolumn{8}{|l|}{ New Jersey } \\
\hline Hunterdon Co. & $\begin{array}{l}\text { April/ } \\
\text { May }\end{array}$ & Tick drag & 5 & $\begin{array}{l}4(80.0)(7,2-14) \\
(0,0,29)\end{array}$ & - & $\begin{array}{l}3(60.0)(5,4-5) \\
(0,0,14)\end{array}$ & - \\
\hline Union Co. & May & $\mathrm{CO}_{2}$ trap & 6 & $1(16.7)(2,2-2)$ & - & $2(33.3)(1,1-1)$ & $4(66.7)(14,2-27)$ \\
\hline \multicolumn{8}{|l|}{ Virginia } \\
\hline \multirow[t]{3}{*}{ Albemarle Co. } & \multirow[t]{3}{*}{ June } & \multirow[t]{2}{*}{$\mathrm{CO}_{2}$ trap } & \multirow[t]{2}{*}{5} & $1(20.0)(1,1-1)$ & $3(60.0)(6,1-15)$ & - & $3(60.0)(374,2-988)$ \\
\hline & & & & $(0,1,0)$ & $(0,6,13)$ & & $(3,802,316)$ \\
\hline & & Tick drag & 16 & $\begin{array}{l}1(6.3)(1,1-1) \\
(0,0,1)\end{array}$ & $\begin{array}{l}6(37.5)(6,1-28) \\
(0,34,4)\end{array}$ & - & $\begin{array}{l}16(100.0)(192,1-1726)^{a} \\
(229,2,780,67)\end{array}$ \\
\hline
\end{tabular}



in the US (Doi, Kata, \& Hayama, 2018). Adult ticks were present on hosts only during our summertime sampling periods, which is consistent with observations in New York (Tufts et al., 2019), where peak adult host-seeking activity occurred from late June to late July.

In its native and introduced ranges, ALT most often is associated with larger mammals (e.g. deer, cattle, sheep), as opposed to small mammals (e.g. rodents) (Heath, 2016; Zheng, Yu, Zhou, Yang, \& Liu, 2012). This favoured association with livestock, combined with an ability to reach extremely high densities in some habitats, can result in production-limiting outcomes for livestock producers (Heath, 2016). In some extreme cases, heavy infestations have led to exsanguination and death of cattle and farmed red deer (Cervus elaphus) (Dicker, 1978; Neilson \& Mossman, 1982). In fact, high-intensity ALT infestations and anaemia were recently reported as the cause of death for several cattle in North Carolina (North Carolina Department of Agriculture \& Consumer Services, 2019). In our surveys, we found that some ALT infestations were intense on some individual hosts, with more than 1,000 ticks on one white-tailed deer and $>50$ ticks on some medium-sized mammals from Virginia. White-tailed deer on Staten Island, New York, also had intense ALT infestations, with 161 ticks collected during $15 \mathrm{~min}$ on one animal (Tufts et al., 2019). Similarly, many cervid host species have been previously documented as hosts for ALT in East Asia, Australia, and New Zealand (Inokuma et al., 2002; Kang et al., 2016; Kim et al., 2011; Neilson \& Mossman, 1982; Yang et al., 2018).

Veterinary and public health officials are concerned that introduced ALT may have also introduced novel/exotic pathogens to their newly established US range, or that they may acquire and transmit native pathogens from resident hosts. The recent report of cattle deaths in Virginia associated with Theileria orientalis Ikeda subtype, a blood parasite that is transmitted by ALT in Australia and causes anaemia, unthriftiness and death, is of immediate concern for US agriculture (Oakes et al., 2019). In addition, this pathogen was recently reported from field-collected ALT from the site of the cattle deaths in Virginia (Thompson et al., 2020). In the US, numerous tick-borne zoonotic pathogens of public health concern already exist in wildlife populations, and each of them is maintained in a specific cycle of reservoir hosts and tick vector species. In the present study, we sampled five rodent species in relatively low numbers, but only woodchucks were infested with ALT. Similarly, Tufts et al. (2019) did not find ALT on 100 rodents surveyed on Staten Island, New York, although sympatric deer were heavily tick-infested. Such small mammals are the typical sylvatic reservoirs of Borrelia burgdorferi and Anaplasma phagocytophilum in the US (Anderson, Johnson, Magnarelli, Hyde, \& Myers, 1986; Stuen, Granquist, \& Silaghi, 2013), but no study to date has found ALT on them. Recently, ALT failed to experimentally transmit the B31 strain of B. burgdorferi to laboratory mice (Breuner et al., 2020), and Ronai, Tufts, and Diuk-Wasser (2020) demonstrated ALT had an actual aversion to association with white-footed mice (Peromyscus leucopus). Collectively, these data suggest that this introduced tick may not become part of the sylvatic cycle of these pathogens, although continued monitoring of the possibility seems justified. Other possible concerns to consider are potential insertion of ALT into the life cycles of human and canine ehrlichiosis agents (e.g. Ehrlichia chaffeensis, E. ewingii and 'Panola 
Mountain' Ehrlichia sp.) that infect white-tailed deer reservoirs, or the cycle of Powassan virus that uses woodchuck and skunk reservoir hosts (Mlera \& Bloom, 2018; Paddock \& Yabsley, 2007; Yabsley, Loftis, \& Little, 2008). These concerns are further highlighted by the ability of ALT to transmit several Ehrlichia spp. and Powassan virus in other regions of the world (Fatmi, Zehra, \& Carpenter, 2017; Lee \& Chae, 2010; Luo et al., 2016; Wei et al., 2016).

Migratory birds can transport ticks over great distances, and ground-dwelling birds can host large numbers of ticks. However, none of the 32 birds we captured and examined were infested with ALT, although our sample size for each species was small. Seven of our sampled bird species were ground-dwelling, and three of them were infested with other tick species. These findings are consistent with those of Tufts et al. (2019), who did not find ALT on 39 birds sampled from Staten Island, New York. However, in its native range and in New Zealand, ALT is sporadically found on migratory birds (Choi et al., 2014; Chong et al., 2018; Kim et al., 2016; Myers, 1924). Regardless, wild turkeys and other Galliformes frequently host native ticks and could be potentially suitable hosts for ALT. Even if migratory birds were to acquire low ALT infestation rates, they could pose a potential risk for long-distance tick movement and dispersal, so additional monitoring for ALT on birds seems warranted (Christopher, William, Lutz, \& Roger, 2000; Lane et al., 2006; Mock, Applegate, \& Fox, 2001).

With the establishment of ALT in the US, four Haemaphysalis species now occur in North America. The rabbit tick ( $H$. leporispalustris) is the most widespread and common, mostly on lagomorph hosts throughout both North America and northern South America. Its immature stages frequently feed on birds, but only rarely on other hosts (Joyce \& Eddy, 1943; Kollars \& Oliver, 2003). Our finding of ALT on a cottontail rabbit in Virginia highlights the importance of accurate specimen identification because this is a very common host for $\mathrm{H}$. leporispalustris, and we observed in our study that both ALT and $H$. leporispalustris can infest a host simultaneously. The other two native New World species are Haemaphysalis chordeilis (a widespread but rarely collected bird tick) and Haemaphysalis juxtakochi (a largely tropical deer tick). The geographic range of $\mathrm{H}$. juxtakochi extends through parts of Mexico, Central and South America, but to date, there is only one published report of this tick outside of quarantine in the US, that is a single adult tick on a white-tailed deer in Ohio (Keirans \& Restifo, 1993). However, immature stages may attach to avian hosts migrating north from the neotropics in the spring, so sporadic introductions of $H$. juxtakochi could be possible (Mukherjee et al., 2014). The three active stages of these four Haemaphysalis spp. are distinguishable, primarily by the morphology of the palps and basis capituli (Egizi et al., 2019). However, for specimens with damaged or missing mouthparts, or when suspected ALT are found in new locations or on new hosts, molecular typing tools are available for species identification (Rainey et al., 2018; Thompson et al., 2020).

In addition to ALT, we also collected specimens of several native US tick species, and most associated data were consistent with their known host and geographic distribution records (Allan, 2001). We did not find A. americanum at either sampling location in New Jersey, despite sampling during seasons when this species would typically be found on hosts. Historically, this tick was absent in New Jersey and other northeastern US states, but it has been increasingly found in the region during the past few decades, including in southern New Jersey (Jordan \& Egizi, 2019; Occi, Egizi, Robbins, \& Fonseca, 2019; Springer, Jarnevich, Barnett, Monaghan, \& Eisen, 2015). We found I. scapularis on more than half of sampled New Jersey passerine birds, highlighting the importance of avian hosts in the local and possibly regional dispersal of this tick species (Ogden et al., 2008). Also, our coupled wildlife and environmental sampling supported a recent study (Koser, 2019) that found examination of wildlife yielded a higher diversity of tick species in a given area when compared with environmental sampling, suggesting that wildlife sampling is a useful method for tick surveillance. Finally, several of the tick species we found (i.e. D. variabilis, A. americanum, I. cookei and I. scapularis) are important vectors of pathogens of veterinary and public health importance, and our data indicates that these ticks are common at some of our sites.

In summary, our data indicates that ALT can use a wide range of wildlife hosts in the US. We report a high infestation prevalence on several hosts (e.g. raccoons, Virginia opossums). We also found a high intensity of infestation on some individual hosts (e.g. $>1,000$ ticks on a single deer found dead). These data are concerning in context to morbidity and mortality previously reported for intensely infested cattle and deer fawns in other regions of the world, and recently in some cattle in the US (Dicker, 1978; Neilson \& Mossman, 1982). Our data, combined with those of Tufts et al. (2019), suggest that wildlife may be important hosts in maintaining ALT. Some of the known wildlife host species of ALT have relatively large home ranges (e.g. deer, fox), so they potentially could serve in dissemination of this invasive tick. However, the movement of infested companion animals and livestock represent other means of long-distance ALT dispersal. Finally, ticks in the US are generally thought to be a primary risk mostly in wooded areas because of the habitat preferences of $D$. variabilis, I. scapularis and A. americanum, but ALT is more often found in grassy habitats and already has been found in well-managed lawns and short-grass areas, including some in full sun (Rainey et al., 2018; Tufts et al., 2019; Wormser et al., 2019). Because many of the wildlife hosts are frequent denizens of peridomestic habitats, this invasive tick could become an issue for domestic animals and people in areas where ticks are not now generally considered a concern.

\section{ACKNOWLEDGEMENTS}

The authors would like to thank the state of Virginia Wildlife Services office and Toby Hairston, as well as Troy Koser (SCWDS) for help with field collections. Primary support for this work was through a cooperative agreement between SCWDS and the US Department of Agriculture (Cooperative Agreements (0312)91130808CA, Veterinary Services, Animal and Plant Health Inspection Service). Partial support for some fieldwork came from the US Department of Agriculture, Wildlife Services. Additional 
financial support to SCWDS was provided by the wildlife management agencies of the member states through the Federal Aid to Wildlife Restoration Act (50 Stat. 917) and by the US Department of the Interior Cooperative Agreement G11AC20003. We thank the National Institutes of Health-funded Post-baccalaureate Research Training in Infectious Disease Research (PREP) Program (GM109435) at UGA for support of KD and the UGA College of Veterinary Medicine for support of ATT. The findings and conclusions in this publication are those of the authors and should not be construed to represent any official USDA or US Government determination or policy.

\section{CONFLICT OF INTEREST}

The authors have no conflict of interest to disclose.

\section{ETHICS STATEMENT}

The authors confirm that the ethical policies of the journal, as noted on the journal's author guidelines page, have been adhered to, and the appropriate ethical review committee approvals have been received for animal use. All animal and sample collection procedures in New Jersey were reviewed and approved by UGA's Institutional Animal Care and Use Committee (IACUC) (A2015 06-017 and A2018 02-010). Animal trapping in Virginia was done under the authority of the USDA Animal Damage Control Act of 1985, in compliance with the National Environmental Policy Act and with the permission of participating landowners. All trapping methods adhered to federal and state laws. Additionally, when used, euthanasia methods followed humane techniques in the American Veterinary Medical Association's Guidelines for the Euthanasia of Animals (Underwood et al., 2013).

\section{DATA AVAILABILITY STATEMENT}

The data that support the findings of this study are available from the corresponding author upon reasonable request.

\section{ORCID}

Seth A. White (iD https://orcid.org/0000-0002-7356-4582 Michael J. Yabsley iD https://orcid.org/0000-0003-2452-5015

\section{REFERENCES}

Allan, S. A. (2001). Ticks (Class Arachnida: Order Acarina). In W. M. Samuel, M. J. Pybus, \& A. A. Kocan (Eds.), Parasitic diseases of wild mammals (pp. 72-106). Ames, IA: lowa State University Press.

Anderson, J. F., Johnson, R. C., Magnarelli, L. A., Hyde, F. W., \& Myers, J. E. (1986). Peromyscus leucopus and Microtus pennsylvanicus simultaneously infected with Borrelia burgdorferi and Babesia microti. Journal of Clinical Microbiology, 23, 135-137. https://doi.org/10.1128/ JCM.23.1.135-137.1986

Beard, C. B., Occi, J., Bonilla, D. L., Egizi, A. M., Fonseca, D. M., Mertins, J. W., ... Bertone, M. A. (2018). Multistate infestation with the exotic disease-vector tick Haemaphysalis longicornis-United States, August 2017-September 2018. Morbidity and Mortality Weekly Report, 67, 1310-1313. https://doi.org/10.15585/mmwr.mm6747a3

Breuner, N. E., Ford, S. L., Hojgaard, A., Osikowicz, L. M., Parise, C. M., Rosales Rizzo, M. F., ... Eisen, L. (2020). Failure of the Asian longhorned tick, Haemaphysalis longicornis, to serve as an experimental vector of the Lyme disease spirochete, Borrelia burgdorferi sensu stricto. Ticks and Tick Borne Diseases, 11, 101311. https://doi. org/10.1016/j.ttbdis.2019.101311

Burridge, M. J. (2011). Non-native and exotic ticks: Threats to human and animal health in the United States. Gaineville, FL: University of Florida Press.

Burridge, M. J., Simmons, L. A., \& Allan, S. A. (2000). Introduction of potential heartwater vectors and other exotic ticks into Florida on imported reptiles. Journal of Parasitology, 86, 700-704. https://doi.org/ 10.1645/0022-3395(2000)086[0700:IOPHVA]2.0.CO;2

Choi, C. Y., Kang, C. W., Kim, E. M., Lee, S., Moon, K. H., Oh, M. R., ... Yun, Y. M. (2014). Ticks collected from migratory birds, including a new record of Haemaphysalis formosensis, on Jeju Island, Korea. Experimental and Applied Acarology, 62, 557-566. https://doi.org/10.1007/s1049 3-013-9748-9

Chong, S., Kim, H. C., Park, J., Choi, C., Klein, T. A., \& Robbins, R. G. (2018). Tick surveillance of migratory birds during 2010-2011 on Hong and Heuksan Islands, Jeollanam Province, Republic of Korea. Systematic and Applied Acarology, 23, 2214-2223. https://doi.org/10.11158/ saa.23.11.13

Christopher, K. W., William, R. D., Lutz, R. S., \& Roger, D. A. (2000). Health status of northern bobwhite quail (Colinus virginianus) in eastern Kansas. Avian Diseases, 44, 953-956. https://doi. org/10.2307/1593071

Clifford, C. M., Anastos, G., \& Van der Borght-Elbl, A. (1961). The larval ixodid ticks of the eastern United States (Acarina-Ixodidae). Entomological Society of America., 2, 15-244.

Dicker, R. W. (1978). The bush tick-An important cattle tick. Agricultural Gazette of New South Wales, 89, 10-12.

Doi, K., Kato, T., \& Hayama, S. I. (2018). Infestation of introduced raccoons (Procyon lotor) with indigenous ixodid ticks on the Miura Peninsula, Kanagawa Prefecture, Japan. International Journal for Parasitology: Parasites and Wildlife, 7, 355-359. https://doi.org/10.1016/j. ijppaw.2018.09.002

Durden, L. A., \& Keirans, J. E. (1996). Nymphs of the genus Ixodes (Acari: Ixodidae) of the United States: Taxonomy, identification key, distribution, hosts, and medical/veterinary importance. Entomological Society of America.

Egizi, A. M., Robbins, R. G., Beati, L., Nava, S., Vans, C. R., Occi, J. L., \& Fonseca, D. M. (2019). A pictorial key to differentiate the recently detected exotic Haemaphysalis longicornis Neumann, 1901 (Acari, Ixodidae) from native congeners in North America. ZooKeys, 818 117-128. https://doi.org/10.3897/zookeys.818.30448

Fatmi, S. S., Zehra, R., \& Carpenter, D. O. (2017). Powassan virus-A new reemerging tick-borne disease. Frontiers in Public Health, 5, 342. https://doi.org/10.3389/fpubh.2017.00342

Greay, T. L., Oskam, C. L., Gofton, A. W., Rees, R. L., Ryan, U. M., \& Irwin, P. J. (2016). A survey of ticks (Acari: Ixodidae) of companion animals in Australia. Parasites \& Vectors, 9, 207. https://doi.org/10.1186/ s13071-016-1480-y

Heath, A. (2016). Biology, ecology and distribution of the tick, Haemaphysalis longicornis Neumann (Acari: Ixodidae) in New Zealand. New Zealand Veterinary Journal, 64, 10-20. https://doi. org/10.1080/00480169.2015.1035769

Heath, A. C., \& Hardwick, S. (2011). The role of humans in the importation of ticks to New Zealand: A threat to public health and biosecurity. Journal of the New Zealand Medical Association, 124, 1-16.

Inokuma, H., Fujimoto, T., Hosoi, E., Tanaka, S., Fujisaki, K., Okuda, M., \& Onishi, T. (2002). Tick infestation of sika deer (Cervus nippon) in the western part of Yamaguchi Prefecture, Japan. Journal of Veterinary Medical Science, 64, 615-617. https://doi.org/10.1292/ jvms.64.615

Iwakami, S., Ichikawa, Y., \& Inokuma, H. (2014). A nationwide survey of ixodid tick species recovered from domestic dogs and cats in 
Japan in 2011. Ticks and Tick Borne Diseases, 5, 771-779. https://doi. org/10.1016/j.ttbdis.2014.05.008

Jordan, R. A., \& Egizi, A. (2019). The growing importance of lone star ticks in a Lyme disease endemic county: Passive tick surveillance in Monmouth County, NJ, 2006-2016. PLoS One, 14, e0211778. https://doi.org/10.1371/journal.pone.0211778

Joyce, C. R., \& Eddy, G. W. (1943). Host and seasonal notes on the rabbit tick, Haemaphysalis leporispalustris. lowa State College Journal of Science, 17, 205-212.

Juliano, S., \& Lounibos, P. (2005). Ecology of invasive mosquitoes: Effects on resident species and on human health. Ecology Letters, 8, 558-574. https://doi.org/10.1111/j.1461-0248.2005.00755

Kang, J. G., Ko, S., Kim, H. C., Chong, S. T., Klein, T. A., Chae, J. B., ... Chae, J. S. (2016). Prevalence of Anaplasma and Bartonella spp. in ticks collected from Korean water deer (Hydropotes inermis argyropus). Korean Journal of Parasitology, 54, 87-91. https://doi.org/10.3347/ kjp.2016.54.1.87

Keirans, J. E., \& Durden, L. A. (1998). Illustrated Key to Nymphs of the Tick Genus Amblyomma (Acari: Ixodidae) Found in the United States. Journal of Medical Entomology, 35(4), 489-495. https://doi. org/10.1093/jmedent/35.4.489

Keirans, J. E., \& Durden, L. A. (2001). Invasion: Exotic ticks (Acari: Argasidae, Ixodidae) imported into the United States. A review and new records. Journal of Medical Entomology, 38, 850-861. https://doi. org/10.1603/0022-2585-38.6.850

Keirans, J. E., \& Litwak, T. R. (1989). Pictorial key to the adults of hard ticks, family Ixodidae (Ixodida: Ixodoidea), east of the Mississippi River. Journal of Medical Entomology, 26, 435-448. https://doi. org/10.1093/jmedent/26.5.435

Keirans, J. E., \& Restifo, R. A. (1993). Haemaphysalis juxtakochi Cooley (Acari: Ixodidae), a Neotropical tick species, found in Ohio. Journal of Medical Entomology, 30, 1074-1075. https://doi.org/10.1093/jmede $\mathrm{nt} / 30.6 .1074$

Kim, B. J., Kim, H., Won, S., Kim, H. C., Chong, S. T., Klein, T. A., ... Chae, J. S. (2014). Ticks collected from wild and domestic animals and natural habitats in the Republic of Korea. Korean Journal of Parasitology, 52, 281-285. https://doi.org/10.3347/kjp.2014.52.3.281

Kim, H. C., Chong, S. T., Choi, C. Y., Nam, H. Y., Chae, H. Y., Klein, T. A., ... Chae, J. S. (2016). Tick surveillance, including new records for three Haemaphysalis species (Acari: Ixodidae) collected from migratory birds during 2009 on Hong Island (Hong-do), Republic of Korea. Systematic and Applied Acarology, 21, 596-606. https://doi. org/10.11158/saa.21.5.4

Kim, H. C., Han, S. H., Chong, S. T., Klein, T. A., Choi, C. Y., Nam, H. Y., ... Chae, J. S. (2011). Ticks collected from selected mammalian hosts surveyed in the Republic of Korea during 2008-2009. Korean Journal of Parasitology, 49, 331-335. https://doi.org/10.3347/ kjp.2011.49.3.331

Kollars, T. M. Jr, \& Oliver, J. H. Jr (2003). Host associations and seasonal occurrence of Haemaphysalis leporispalustris, Ixodes brunneus, I.cookei, I. dentatus, and I. texanus (Acari: Ixodidae) in southeastern Missouri. Journal of Medical Entomology, 40, 103-107. https://doi. org/10.1603/0022-2585-40.1.103

Koser, T. M. (2019). Comparison of different surveillance methods for modeling dispersal of ticks (Unpublished master's thesis). Athens, GA: The University of Georgia.

Lane, R. S., Kucera, T. F., Barrett, R. H., Mun, J., Wu, C., \& Smith, V. S. (2006). Wild turkey (Meleagris gallopavo) as a host of ixodid ticks, lice, and Lyme disease spirochetes (Borrelia burgdorferi sensu lato) in California state parks. Journal of Wildlife Diseases, 42, 759-771. https://doi.org/10.7589/0090-3558-42.4.759

Lee, M.-J., \& Chae, J.-S. (2010). Molecular detection of Ehrlichia chaffeensis and Anaplasma bovis in the salivary glands from Haemaphysalis longicornis ticks. Vector-Borne and Zoonotic Diseases, 10, 411-413. https://doi.org/10.1089/vbz.2008.0215
Lounibos, L. P. (2002). Invasions by insect vectors of human disease. Annual Review of Entomology, 47, 233-266. https://doi.org/10.1146/ annurev.ento.47.091201.145206

Luo, L., Sun, J., Yan, J., Wang, C., Zhang, Z., Zhao, L., ... Yu, X. J. (2016). Detection of a novel Ehrlichia species in Haemaphysalis longicornis tick from China. Vector Borne and Zoonotic Diseases, 16, 363-367. https://doi.org/10.1089/vbz.2015.1898

McFadden, A., Vink, D., Pulford, D., Lawrence, K., Gias, E., Heath, A., ... Bingham, P. (2016). Monitoring an epidemic of Theileria-associated bovine anaemia (Ikeda) in cattle herds in New Zealand. Preventive Veterinary Medicine, 125, 31-37. https://doi.org/10.1016/j.preve tmed.2015.11.005

Mlera, L., \& Bloom, M. E. (2018). The role of mammalian reservoir hosts in tick-borne flavivirus biology. Frontiers in Cellular and Infection Microbiology, 8, 298. https://doi.org/10.3389/ fcimb.2018.00298

Mock, D. E., Applegate, R. D., \& Fox, L. B. (2001). Preliminary survey of ticks (Acari: Ixodidae) parasitizing wild turkeys (Aves: Phasianidae) in eastern Kansas. Journal of Medical Entomology, 38, 118-121. https:// doi.org/10.1603/0022-2585-38.1.118

Molaei, G., Karpathy, S. E., \& Andreadis, T. G. (2019). First report of the introduction of an exotic tick, Amblyomma coelebs (Acari: Ixodidae), feeding on a human traveler returning to the United States from Central America. Journal of Parasitology, 105, 571-575. https://doi. org/10.1645/19-74

Mukherjee, N., Beati, L., Sellers, M., Burton, L., Adamson, S., Robbins, R. G., ... Karim, S. (2014). Importation of exotic ticks and tick-borne spotted fever group rickettsiae into the United States by migrating songbirds. Ticks and Tick Borne Diseases, 5, 127-134. https://doi. org/10.1016/j.ttbdis.2013.09.009

Myers, J. (1924). The cattle-tick (Haemaphysalis bispinosa) investigations during 1923-24. Bulletin of the New Zealand Department of Agriculture, 116, 1-105.

Neilson, F. J., \& Mossman, D. H. (1982). Anaemia and deaths in red deer (Cervus elaphus) fawns associated with heavy infestations of cattle tick (Haemaphysalis longicornis). New Zealand Veterinary Journal, 30, 125-126. https://doi.org/10.1080/00480169.1982.34908

North Carolina Department of Agriculture and Consumer Services. (2019). State Veterinarian reminds livestock and pet owners to watch out for ticks. Retrieved from http://www.ncagr.gov/paffairs/.

Oakes, V. J., Yabsley, M. J., Schwartz, D., LeRoith, T., Bissett, C., Broaddus, C., ... Lahmers, K. K. (2019). Theileria orientalis Ikeda genotype in cattle, Virginia, USA. Emerging Infectious Diseases, 25, 1653-1659. https://doi.org/10.3201/eid2509.190088

Occi, J. L., Egizi, A. M., Robbins, R. G., \& Fonseca, D. M. (2019). Annotated list of the hard ticks (Acari: Ixodida: Ixodidae) of New Jersey. Journal of Medical Entomology, 56, 589-598. https://doi.org/10.1093/jme/ tjz010

Ogden, N. H., Lindsay, L. R., Hanincová, K., Barker, I. K., Bigras-Poulin, M., Charron, D. F., ... Thompson, R. A. (2008). Role of migratory birds in introduction and range expansion of Ixodes scapularis ticks and of Borrelia burgdorferi and Anaplasma phagocytophilum in Canada. Applied and Environmental Microbiology, 74, 1780-1790. https://doi. org/10.1128/AEM.01982-07

Paddock, C. D., \& Yabsley, M. J. (2007). Ecological havoc, the rise of white-tailed deer, and the emergence of Amblyomma americanum-associated zoonoses in the United States. Current Topics in Microbiology and Immunology, 315, 289-324. https://doi.org/10.1007/978-3-54070962-6_12

Pietzsch, M., Quest, R., Hillyard, P. D., Medlock, J. M., \& Leach, S. (2006). Importation of exotic ticks into the United Kingdom via the international trade in reptiles. Experimental and Applied Acarology, 38, 59-65. https://doi.org/10.1007/s10493-005-5318-0

Rainey, T., Occi, J. L., Robbins, R. G., \& Egizi, A. (2018). Discovery of Haemaphysalis longicornis (Ixodida: Ixodidae) parasitizing a sheep in 
New Jersey, United States. Journal of Medical Entomology, 55, 757759. https://doi.org/10.1093/jme/tjy006

Ronai, I., Tufts, D. M., \& Diuk-Wasser, M. A. (2020). Aversion of the invasive Asian longhorned tick to the white-footed mouse, the dominant reservoir of tick-borne pathogens in the U.S.A. Medical and Veterinary Entomology, https://doi.org/10.1111/mve.12441

Springer, Y. P., Jarnevich, C. S., Barnett, D. T., Monaghan, A. J., \& Eisen, R. J. (2015). Modeling the present and future geographic distribution of the lone star tick, Amblyomma americanum (Ixodida: Ixodidae), in the continental United States. American Journal of Tropical Medicine and Hygeine, 93, 875-890. https://doi.org/10.4269/ajtmh.15-0330

Stuen, S., Granquist, E., \& Silaghi, C. (2013). Anaplasma phagocytophilum-A widespread multi-host pathogen with highly adaptive strategies. Frontiers in Cellular and Infection Microbiology, 3, 31. https://doi. org/10.3389/fcimb.2013.00031

Thompson, A. T., Dominguez, K., Cleveland, C. A., Dergousoff, S. J., Doi, K., Falco, R. C., ... Yabsley, M. (2020). Molecular characterization of Haemaphysalis species and a molecular genetic key for the identification of Haemaphysalis of North America. Frontiers in Veterinary Science, 514107, https://doi.org/10.3389/fvets.2020.00141

Tufts, D. M., VanAcker, M. C., Fernandez, M. P., DeNicola, A., Egizi, A., \& Diuk-Wasser, M. A. (2019). Distribution, host-seeking phenology, and host and habitat associations of Haemaphysalis longicornis ticks, Staten Island, New York, USA. Emerging Infectious Diseases, 25, 792796. https://doi.org/10.3201/eid2504.181541

Underwood, W., Anthony, R., Cartner, S., Corey, D., Grandin, T., Greenacre, C. B., ... Miller, D. (2013). AVMA guidelines for the euthanasia of animals: 2013 edition. Schaumburg, IL: American Veterinary Medical Association.

Wei, F., Song, M., Liu, H., Wang, B., Wang, S., Wang, Z., ... Liu, Q. (2016). Molecular detection and characterization of zoonotic and veterinary pathogens in ticks from northeastern China. Frontiers in Microbiology, 7, 1913. https://doi.org/10.3389/fmicb.2016.01913
Wormser, G. P., McKenna, D., Piedmonte, N., Vinci, V., Egizi, A. M., Backenson, B., \& Falco, R. C. (2020). First recognized human bite in the United States by the Asian Longhorned Tick, Haemaphysalis longicornis. Clinical Infectious Diseases, 70(2), 314-316. https://doi. org/10.1093/cid/ciz449

Yabsley, M. J., Loftis, A. D., \& Little, S. E. (2008). Natural and experimental infection of white-tailed deer (Odocoileus virginianus) from the United States with an Ehrlichia sp. closely related to Ehrlichia ruminantium. Journal of Wildlife Diseases, 44, 381-387. https://doi. org/10.7589/0090-3558-44.2.381

Yang, Y., Yang, Z., Kelly, P., Li, J., Ren, Y., \& Wang, C. (2018). Borrelia miyamotoi sensu lato in Père David deer and Haemaphysalis longicornis ticks. Emerging Infectious Diseases, 24, 928-931. https://doi. org/10.3201/eid2405.171355

Yu, X.-J., Liang, M.-F., Zhang, S.-Y., Liu, Y., Li, J.-D., Sun, Y.-L., ... Li, D.-X. (2011). Fever with thrombocytopenia associated with a novel bunyavirus in China. New England Journal of Medicine, 364, 1523-1532. https://doi.org/10.1056/NEJMoa1010095

Zheng, H., Yu, Z., Zhou, L., Yang, X., \& Liu, J. (2012). Seasonal abundance and activity of the hard tick Haemaphysalis longicornis (Acari: Ixodidae) in North China. Experimental and Applied Acarology, 56, 133-141. https://doi.org/10.1007/s10493-011-9505-x

How to cite this article: White SA, Bevins SN, Ruder MG, et al. Surveys for ticks on wildlife hosts and in the environment at Asian longhorned tick (Haemaphysalis longicornis)-positive sites in Virginia and New Jersey, 2018. Transbound Emerg Dis. 2021;68:605-614. https://doi.org/10.1111/tbed.13722 